\title{
CARACTERIZAÇÃO DAS RAÍZES E FÉCULAS DE TRÊS VARIEDADES DE MANDIOCA PRODUZIDAS NO ESTADO DO PARÁ
}

\author{
Priscilla Andrade Silva ${ }^{1}$, Wellington dos Santos Melo ${ }^{1}$, Roberto Lisboa Cunha ${ }^{2}$, Elisa \\ Ferreira Moura Cunha ${ }^{3}$, Alessandra Santos Lopes ${ }^{4}$, Rosinelson da Silva Pena ${ }^{5}$
}

\begin{abstract}
RESUMO
O Pará é o maior produtor brasileiro de mandioca (Manihot esculenta Crantz), a qual e destinada principalmente para a obtenção da farinha de mesa, embora a fécula seja o produto mais nobre extraído das suas raízes. O objetivo deste trabalho foi caracterizar as raízes ecas féculas de três variedades de mandioca produzidas no estado do Pará. A análise biométrica constatou que não há um padrão de tamanho e de forma para as raízes de mandioca. As féculas obtidas apresentaram elevada pureza em amido $(>92 \%)$ e foram classificadas como "fécula tipo 1", pela legislação brasileira. De acordo com a microscopia eletrônica de varredura, os grânulos de amido das féculas apresentaram forma arredondada e ligeiramente achatada em uma das extremidades, com superfície lisa e tamanhos diferentes para as três variedades. As temperaturas de gelatinização dos amidos das três féculas $\left(T_{p}=74,4{ }^{\circ} \mathrm{C}\right)$ não apresentaram diferença significativa $(\mathrm{p} \geq 0,05)$, porém o amido extraído da variedade Pai Ambrósio apresentou a maior entalpia de gelatinização $\left(\Delta \mathrm{H}_{\text {gel }}=5,88 \mathrm{~J} / \mathrm{g}\right)$.
\end{abstract}

Palavras-chave: Manihot esculenta, amido, propriedades, MEV, DSC.

\section{CARACTERIZATION OF ROOTS AND CASSAVA STARCH FROM THREE CASSAVA VARIETIES PRODUCED IN THE STATE OF PARÁ}

\begin{abstract}
\end{abstract}
The state of Pará is the largest brazilian producer of cassava (Manihot esculenta Crantz), which is mainly used to obtain the cassava flour, although the cassava starch is the most valuable product extracted from its roots. The objective of this study was to characterize three varieties of cassava roots produced in Pará and the starch extracted of them. According to the biometric analysis, there is no size or shape pattern for the cassava roots. All cassava starches presented high starch content $(>92 \%)$ and were classified as "cassava starch type 1", according to Brazilian legislation. According to scanning electron microscopy (SEM), the starch granules of cassava starches were circular in shape and had some concave-convex characteristics, with smooth surface and different sizes for the three cassava varieties. The starch gelatinization temperature of the three cassava starches studied $\left(\mathrm{T}_{\mathrm{p}}=74.4^{\circ} \mathrm{C}\right)$ showed no significant difference $(\mathrm{p}>0.05)$, but the cassava starch extracted from the variety called Pai Ambrósio presented the highest gelatinization enthalpy $\left(\Delta \mathrm{H}_{\text {gel }}=5.88 \mathrm{~J} / \mathrm{g}\right)$.

Keywords: Manihot esculenta, starch, propertie, SEM, DSC.

\footnotetext{
Protocolo 17201505 de 09/02/2015

${ }^{1}$ Mestre em Ciência e Tecnologia de Alimentos, Universidade Federal do Pará (UFPA), Belém, PA, Brasil. E-mail: prisciandra@yahoo.com.br; wsm eng@yahoo.com.br

${ }^{2}$ Doutor em Ciências Agrárias, Pesquisador, Embrapa Amazônia Oriental, Belém, PA, Brasil. E-mail: roberto.cunha@embrapa.br

3 Doutora em Genética e Melhoramento, Pesquisador, Embrapa Amazônia Oriental, Belém, PA, Brasil. E-mail: elisa.moura@embrapa.br

${ }^{4}$ Doutora em Tecnologia de Alimentos, Docente, Faculdade de Engenharia de Alimentos, Instituto de Tecnologia, UFPA, Belém, PA, Brasil. E-mail: aslopes@ufpa.br

5 Doutor em Engenharia Química, Docente, Faculdade de Engenharia de Alimentos, Instituto de Tecnologia, UFPA, Rua Augusto Corrêa, 01 - Guamá, 66075-900, Belém, PA, Brasil. E-mail: rspena@ufpa.br
} 


\section{INTRODUÇÃO}

A mandioca (Manihot esculenta Crantz) é uma espécie de grande interesse agronômico, que se adaptada bem às condições edafoclimáticas brasileiras e é tolerante aos estresses bióticos e abióticos, podendo apresentar rendimentos elevados até mesmo em solos já esgotados por outras culturas (Embrapa, 2005). Essa cultura tem um papel importante no Brasil, tanto como fonte de energia e na alimentação humana e animal, quanto como geradora de emprego e de renda, principalmente em áreas pobres. No estado do Pará a mandioca é a principal fonte de carboidrato para uma significativa parcela da população de menor poder aquisitivo, e passou a ter importância econômica para os municípios produtores e para o Estado, através da comercialização da farinha de mandioca (Chisté et al., 2007).

Entre os produtos e subprodutos da mandioca, o mais versátil e valorizado é a fécula, denominação que a Legislação Brasileira dá à fração amilácea originária de raízes e tubérculos (Brasil, 2005). A fécula de mandioca, conhecida também, em algumas regiões brasileiras, como polvilho doce ou goma, é um pó fino, branco, inodoro, insípido, que produz ligeira crepitação quando comprimido entre os dedos (Silva et al. 2013). É um polissacarídeo natural constituído por amilose e amilopectina, obtido das raizes da mandioca, após descascamento, trituração, desintegração, purificação, peneiramento, centrifugação, concentração e secagem. Têm ampla aplicação em diyersos setores como indústria têxtil, de papel, farmacêutica, siderúrgica, plástica e alimentícia (Cereda \& Vilpoux, 2003).

A fécula de mandioca é constituída, em média, por $18 \%$ de amilose e $82 \%$ de amilopectina. A amilose é uma molécula essencialmente linear formada por unidades de glicose ligadas em $\alpha-1,4$, e apresenta pequeno número de ramificações, enquanto a amilopectina é uma molécula altamente ramificada, também composta de unidades de glicose ligadas em $\alpha-1,4$, mas com 5 a $6 \%$ de ligações em $\alpha-1,6$, nos pontos de ramificação (Nwokocha et al., 2009).

A compreensão da estrutura dos grânulos de amido é importante no entendimento de suas propriedades físico-químicas, as quais determinam o comportamento do amido natural ou modificado, nos mais diversos processos industriais aos quais eles normalmente são submetidos. Em termos da organização dos grânulos e da estrutura de seus constituintes poliméricos, cada amido é único. Grupos de plantas (cereais, raízes, leguminosas e tubérculos) e mesmo plantas da mesma espécie, apresentam amidos com características e propriedades diferentes (Ratnayake \& Jackson, 2007).

Este trabalho teve como objetivo caracterizar as raízes de três variedades de mandioca produzidas estado do Pará (Pai Ambrósio, Pocu e Paulo Velho), e as féculas (amidos) extraídas das mesmas, através de avaliação físicoquímica, morfológica e térmica.

\section{MATERIAL E MÉTODOS}

\section{Matéria-prima}

Foram estudadas as raízes das três variedades de mandioca mais utilizadas pelos produtores de fécula e de farinha de tapioca, no estado do Pará, sendo: Pai Ambrósio, procedente do município de Acará (PA); Pocu, procedente do município de Santo Antônio do Tauá (PA) e Paulo Velho, procedente do município de Ourém - Comunidade de Patauateua (PA). Todas as raízes apresentavam, em média, 14 meses de plantio.

\section{Caracterização física das raízes}

30 raízes de cada variedade de mandioca foram escolhidas aleatoriamente para a realização da análise biométrica. Com auxílio de um paquímetro metálico de $300 \mathrm{~mm}$ marca Vonder foram feitas as medidas de comprimento e largura das raízes, e o rendimento em polpa das mesmas foi determinado pela relação mássica raiz sem casca/raiz integral.Obtenção das féculas

As etapas realizadas na obtenção das féculas das raízes das três variedades de mandioca foram: lavagem em água corrente, descascamento, sanitização $(100 \mathrm{mg} \mathrm{Cl} / \mathrm{L}$ por $20 \mathrm{~min}$ ), trituração, peneiramento e lavagem da massa, sedimentação $\left(25^{\circ} \mathrm{C} / 24 \mathrm{~h}\right)$, lavagem e purificação da fécula, secagem a $60^{\circ} \mathrm{C}$, moagem, acondicionamento a vácuo em sacos de polietileno $(\approx 200 \mathrm{~g})$ e armazenamento à temperatura ambiente $\left(\approx 25^{\circ} \mathrm{C}\right)$.

\section{Caracterização físico-química das féculas}

Foram realizadas as seguintes análises: umidade - por gravimetria, método 920.151 da 
AOAC (1997); $p H$ - por potenciometria, método 981.12 da AOAC (1997); acidez total titulável - segundo método 02-31 da AACC (1995); atividade de água $\left(a_{w}\right)$ - através de leitura direta em termohigrômetro digital; proteinas totais - por Kjeldahl, método 920.87 da AOAC (1997), com fator de correspondência nitrogênio-proteína de 5,75 (proteínas vegetais) (Brasil, 2003); lipídios - pelo método 922.06 da AOAC (1997); cinzas - através do método 930.05 da AOAC (1997); amido total conforme metodologia proposta por Cereda et al. (2004); cor instrumental - por colorimetria tristimulus, através de leitura direta em colorímetro digital da marca KONICAMINOLTA, modelo CR 400, pelo sistema CIE Lab.

\section{Análise morfológica das féculas}

A caracterização morfológica dos grânulos de amido das féculas foi realizada por microscopia eletrônica de varredura (MEV), em equipamento modelo LEO-1430, com corrente do feixe de elétrons de $90 \mu \mathrm{A}$, voltagem de aceleração constante de $15 \mathrm{kv}$, distância de trabalho de $15 \mathrm{~mm}$ e elétrons secundários como tipo de imagens.

\section{Análise térmica das féculas}

A análise térmica foi realizada em analisador térmico diferencial e gravimétrico, da marca Shimadzu, modelo DTG-60H, com razão de aquecimento de $15^{\circ} \mathrm{C} / \mathrm{min}$ e fluxo de ar sintético de $25 \mathrm{~mL} / \mathrm{min}$, na faixa de temperatura de 30 a $525^{\circ} \mathrm{C}$. A determinação da temperatura de gelatinização dos amidos das féculas foi realizada com uma suspensão aquosa da fécula a $20 \%$, por calorimetria diferencial de varredura (DSC), em equipamento Shimadzu, modelo DSC-60, eom razão de aquecimento de $10^{\circ} \mathrm{C} / \mathrm{min}$ e fluxo de nitrogênio de $25 \mathrm{~mL} / \mathrm{min}$, na faixa de temperatura de 30 a $150^{\circ} \mathrm{C}$, de acordo com Garcia et al. (1996).

\section{Análise estatística}

As análises físicas das raízes e físicoquímicas das féculas foram realizadas em triplicata e os resultados foram avaliados através de análise de variância (ANOVA) e teste complementar de comparação de médias de Tukey, com auxílio do programa STATISTICA Kernel Release 7.1 (StatSoft Inc., 2006, Tulsa, OK, USA).

\section{RESULTADOS E DISCUSSÄO \\ Caracterização física das raízes}

O rendimento em polpa das raízes de mandioca foi de $68,6 \%( \pm 0,81), 88,0 \%( \pm 0,02)$ e $87,8 \% \quad( \pm 0,35)$ para as variedades Pai Ambrósio, Pocu e Paulo Velho, respectivamente. As variedades Pocu e Paulo Velho rendimentos estatisticamente iguais $(\mathrm{p}>0,05)$, e åproximadamente $20 \%$ superior ao observado para a variedade Pai Ambrósio. Os resultados indicam que as raízes das variedades Pocu e Paulo Velho podem proporcionar maiores rendimentos industriais.

As características biométricas das três raízes estudadas são apresentadas na Tabela 1. $\mathrm{O}$ comprimento, o diâmetro da parte superior e o diâmetro da parte intermediária das raízes foram diferentes $(p \leq 0,05)$, para pelo menos uma variedade, enquanto o diâmetro menor e o peso médio das raízes não apresentaram diferença significativa $(\mathrm{p}>0,05)$. Adetan et al. (2003) observaram diâmetro médio superior $(8,8 \mathrm{~cm})$ para raízes de uma cultivar de mandioca nigeriana, e Gomes et al. (2007) determinaram comprimento médio também superior $(22,6 \mathrm{~cm})$, entre 100 clones de raízes de mandiocas brasileiras.

Tabela 1. Valor médio e desvio-padrão para os parâmetros biométricos das raízes das três variedades de mandioca.

\begin{tabular}{lccc}
\hline \multirow{2}{*}{\multicolumn{1}{c}{ Parâmetro }} & \multicolumn{3}{c}{ Variedade da mandioca } \\
\cline { 2 - 4 } & Pai Ambrósio & Pocu & Paulo Velho \\
\hline Comprimento (cm) & $18,2 \pm 4,28^{\mathrm{a}}$ & $16,5 \pm 6,24^{\mathrm{b}}$ & $18,1 \pm 7,23^{\mathrm{a}}$ \\
Diâmetro da parte superior (cm) & $6,16 \pm 1,26^{\mathrm{a}}$ & $4,99 \pm 1,12^{\mathrm{b}}$ & $4,52 \pm 1,21^{\mathrm{b}}$ \\
Diâmetro da parte intermediária $(\mathrm{cm})$ & $6,45 \pm 1,39^{\mathrm{a}}$ & $5,76 \pm 1,31^{\mathrm{ab}}$ & $5,21 \pm 1,51^{\mathrm{b}}$ \\
Diâmetro da parte inferior $(\mathrm{cm})$ & $2,98 \pm 0,89^{\mathrm{a}}$ & $2,84 \pm 0,91^{\mathrm{a}}$ & $2,89 \pm 0,78^{\mathrm{a}}$ \\
Peso médio da raiz $(\mathrm{g})$ & $387,9 \pm 173,8^{\mathrm{a}}$ & $353,4 \pm 197,05^{\mathrm{a}}$ & $341,1 \pm 255,02^{\mathrm{a}}$ \\
\hline
\end{tabular}

Médias com letras iguais, na mesma linha, não diferem entre si pelo Teste de Tukey $(p>0,05)$. 
Os desvios-padrões representaram mais de $20 \%$ das médias para os parâmetros comprimento e diâmetro, e mais de $45 \%$ para o parâmetro peso médio da raiz, o que evidencia a inexistência de um padrão de tamanho e de forma para as raízes de uma mesma variedade.

\section{Caracterização físico-química das féculas}

A composição e os parâmetros físico-químicos das três féculas são apresentados na Tabela 2, bem como e o rendimento em fécula em relação às raízes sem casca. Os teores de umidade $(<14 \%)$, amido
$(>80 \%)$, cinzas $(<0,75 \%)$ e o $\mathrm{pH}(4,0-7,0)$ das féculas atenderam a legislação brasileira (Brasil, 2005), de acordo com a qual as féculas são classificadas como "fécula tipo 1". A acidez e os teores de proteínas, lipídios e cinzas das féculas seguiram as mesmas tendências observadas por Leonel (2007) (1,05 meq $\mathrm{NaOH} / 100 \mathrm{~g})$, Charles et al. (2007) $(0,08 \%)$, Cereda \& Vilpox (2003) $(0,10 \%)$ e Charles et al. (2007) $(0,04 \%)$, respectivamente. $\mathrm{A} \mathrm{a}_{\mathrm{w}}$ inferior a 0,6 para todos as féculas assegura a estabilidade microbiológica dos produtos (Jay, 2005).

Tabela 2. Valor médio e desvio-padrão para a composição, propriedades físico-químicas e rendimento de extração das féculas das três variedades de mandioca.

\begin{tabular}{|c|c|c|c|}
\hline \multirow{2}{*}{ Parâmetros } & \multicolumn{3}{|c|}{ Variedade da mandioca } \\
\hline & Pai Ambrósio & Pocu & Paulo Velho \\
\hline$\overline{\text { Umidade }(\%)}$ & $8,22 \pm 0,08^{\mathrm{c}}$ & $13,64 \pm 0,08^{\mathrm{a}}$ & $10,48 \pm 0,18^{b}$ \\
\hline Proteínas $(\%)^{1}(\mathrm{~N} \times 5,75)$ & $0,09 \pm 0,00^{\mathrm{a}}$ & $0,09 \pm 0,00^{\mathrm{a}}$ & $0,09 \pm 0,00^{\mathrm{a}}$ \\
\hline Lipídios $(\%)^{1}$ & $0,26 \pm 0,02^{\mathrm{a}}$ & $0,26 \pm 0,04$ & $0,25 \pm 0,01^{\mathrm{a}}$ \\
\hline Cinzas $(\%)^{1}$ & $0,08 \pm 0,01^{\mathrm{a}}$ & $0,06 \pm 0,01^{a}$ & $0,08 \pm 0,02^{\mathrm{a}}$ \\
\hline Amido $(\%)^{1}$ & $97,46 \pm 0,28^{\mathrm{a}}$ & $96,55 \pm 0,35^{\mathrm{a}}$ & $92,47 \pm 0,73^{b}$ \\
\hline Atividade de água $\left(\mathrm{a}_{\mathrm{w}}\right)$ & $0,26 \pm 0,01^{c}$ & $0,52 \pm 0,01^{\mathrm{a}}$ & $0,39 \pm 0,00^{\mathrm{b}}$ \\
\hline Acidez titulável $^{2}$ & $0,89 \pm 0,00^{\mathrm{b}}$ & $\pm 0,01^{\mathrm{a}}$ & $0,96 \pm 0,00^{\mathrm{a}}$ \\
\hline $\mathrm{pH}$ & $6,21 \pm 0,14^{\mathrm{a}}$ & $6,06 \pm 0,13^{\mathrm{a}}$ & $6,03 \pm 0,09^{\mathrm{a}}$ \\
\hline Cor L* & $97,00 \pm 0,80^{\mathrm{a}}$ & $97,30 \pm 0,20^{\mathrm{a}}$ & $97,03 \pm 0,58^{\mathrm{a}}$ \\
\hline$a^{*}$ & $0,14 \pm 0,03^{b}$ & $0,15 \pm 0,06^{\mathrm{ab}}$ & $0,21 \pm 0,04^{\mathrm{a}}$ \\
\hline$b^{*}$ & $1,26 \pm 0,53^{\mathrm{a}}$ & $1,21 \pm 0,05^{\mathrm{a}}$ & $1,67 \pm 0,08^{\mathrm{a}}$ \\
\hline Rendimento em fécula (\%) & $6,80 \pm 0,07^{\mathrm{c}}$ & $15,50 \pm 0,09^{a}$ & $10,70 \pm 0,11^{\mathrm{b}}$ \\
\hline
\end{tabular}

${ }^{1}$ Valores em base seca; ${ }^{2}$ meq NaOH/100g. Médias com letras iguais, na mesma linha, não diferem entre si pelo Teste de Tukey $(\mathrm{p}>0,05)$.

O elevado teor de amido $(>92 \%)$ e o baixo teor dos constituintes não amiláceos $(<8 \%)$, juntamente com a combinação dos parâmetros de cor: $\mathrm{L}^{*}$ próxímo a $100, \mathrm{a}^{*} \mathrm{e} \mathrm{b}^{*}$ próximos a zero, que asseguram a brancura dos produtos, indicam a excelente qualidade das féculas extraídas das três variedades de mandioca, em especial das variedades Pai Ambrósio e Pocu.

Os rendimentos de extração das féculas foram inferiores às médias observadas por Nunes et al. (2009) $(20,64-33,25 \%)$ para três variedades de mandioca do semiárido baiano. As raízes das variedades Pocu e Paulo Velho, que apresentaram o maior rendimento em polpa, foram também as que apresentaram os maiores rendimentos em fécula, o que confirma a potencialidade industrial dessas variedades.

\section{Análise morfológica das féculas}

Os grânulos de amido das féculas das três variedades de mandioca apresentaram forma arredondada e ligeiramente achatada em uma das extremidades, com superfície lisa (Figura 1); mesma forma observada por Leonel (2007) para amido de mandioca. Alguns grânulos apresentaram depressões na superfície, conferindo aspecto e formato irregular, truncado. Os diâmetros dos grânulos de amido das féculas variaram de 2 a $30 \mu \mathrm{m}, 2$ a $20 \mu \mathrm{m}$ e 10 a $20 \mu \mathrm{m}$, para as variedades de mandioca Pai Ambrósio, Pocu e Paulo Velho, respectivamente. Leonel (2007) observaram diâmetros entre 14,4 e $17,1 \mu \mathrm{m}$ e Cereda \& Vilpoux (2003) entre 10 e $15 \mu \mathrm{m}$, para amidos de mandioca. 


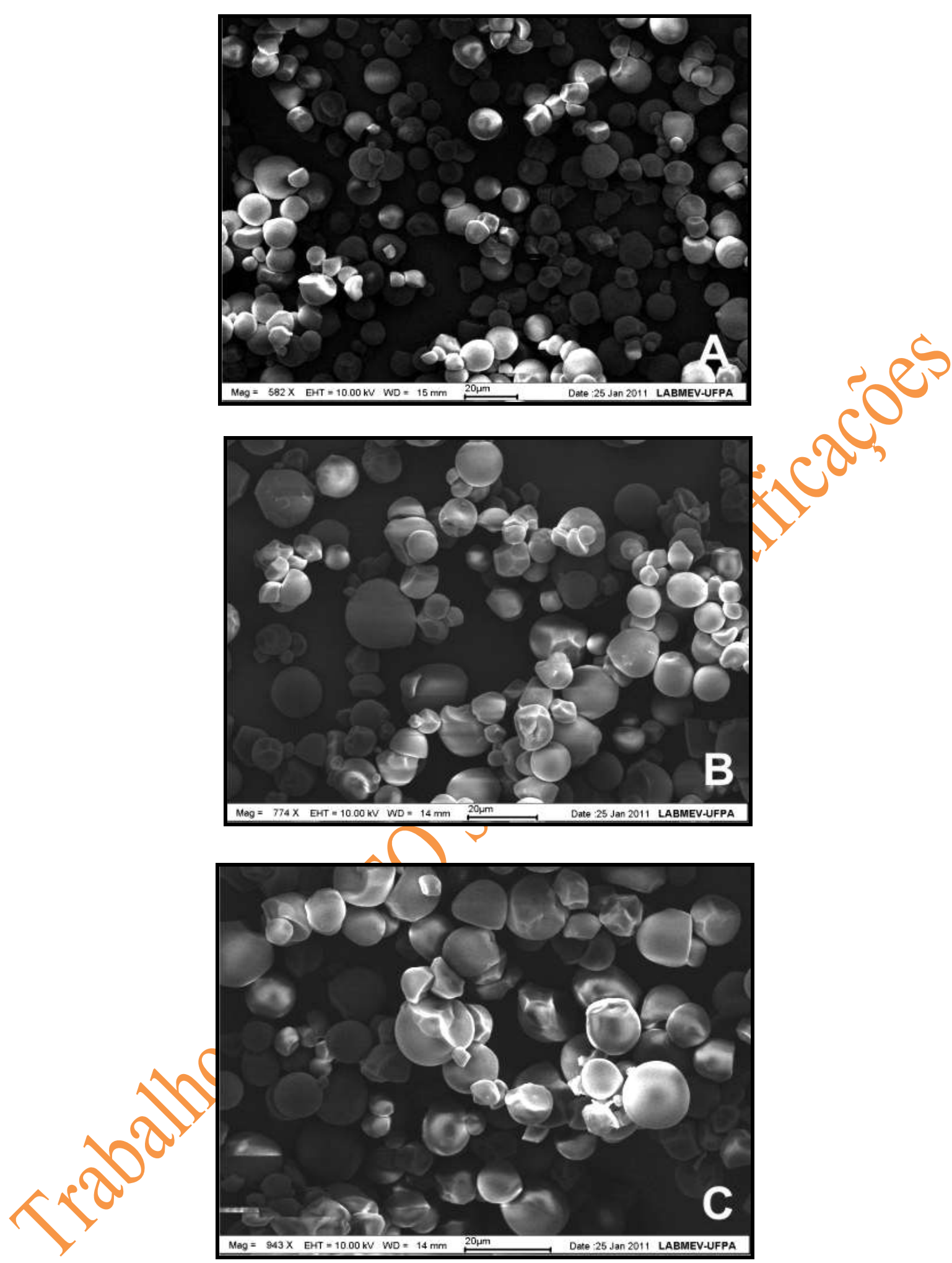

Figura 1. Eletromicrografias dos grânulos de amido das féculas extraídas das mandiocas variedade: (a) Pai Ambrósio, (b) Pocu e (c) Paulo Velho.

\section{Análise térmica das féculas}

Os resultados das análises térmicas diferencial (DTA) e gravimétrica (TG) são apresentados na Figura 2, onde pode ser observado que as três féculas apresentaram o mesmo padrão térmico. Nas curvas TG foram detectados três eventos principais de perda de massa; o primeiro referente a um processo de desidratação e os demais a processos de decomposição, com base nas energias envolvidas. $\mathrm{O}$ primeiro evento, que ocorreu 
entre $43,0^{\circ} \mathrm{C}$ e $106,7^{\circ} \mathrm{C}$ e provocou uma perda de massa de 11,4 a $13,7 \%$, é atribuído à perda de umidade das féculas, representada por um pico endotérmico característico de desidratação, nas curvas DTA.

Entre $106,7^{\circ} \mathrm{C}$ e $302,0^{\circ} \mathrm{C}$ não ocorreu nenhuma perda de massa (TG) ou evento térmico (DTA), quando iniciou o segundo evento, que se estendeu até $336,5^{\circ} \mathrm{C}$ e provocou perda de massa das féculas de 72,2 a $75,1 \%$. Sequencialmente iniciou o terceiro evento que se estendeu até $526,8^{\circ} \mathrm{C}$, mas apesar de ter ocorrido em uma faixa mais ampla de temperatura, só provocou 4,0 a $8,2 \%$ de perda de massa. Esses eventos são atribuídos à decomposição térmica da amilose e da amilopectina das féculas, confirmada pelos picos exotérmicos nas curvas DTA. A quebra de algumas ligações, particularmente da amilopectina, pode ter contribuído para a desintegração dos grânulos em altas temperaturas. Segundo Aggarwal et al. (1997), o tratamento térmico de amidos normalmente provoca a sua despolimerização, quando a temperatura excede $300^{\circ} \mathrm{C}$.
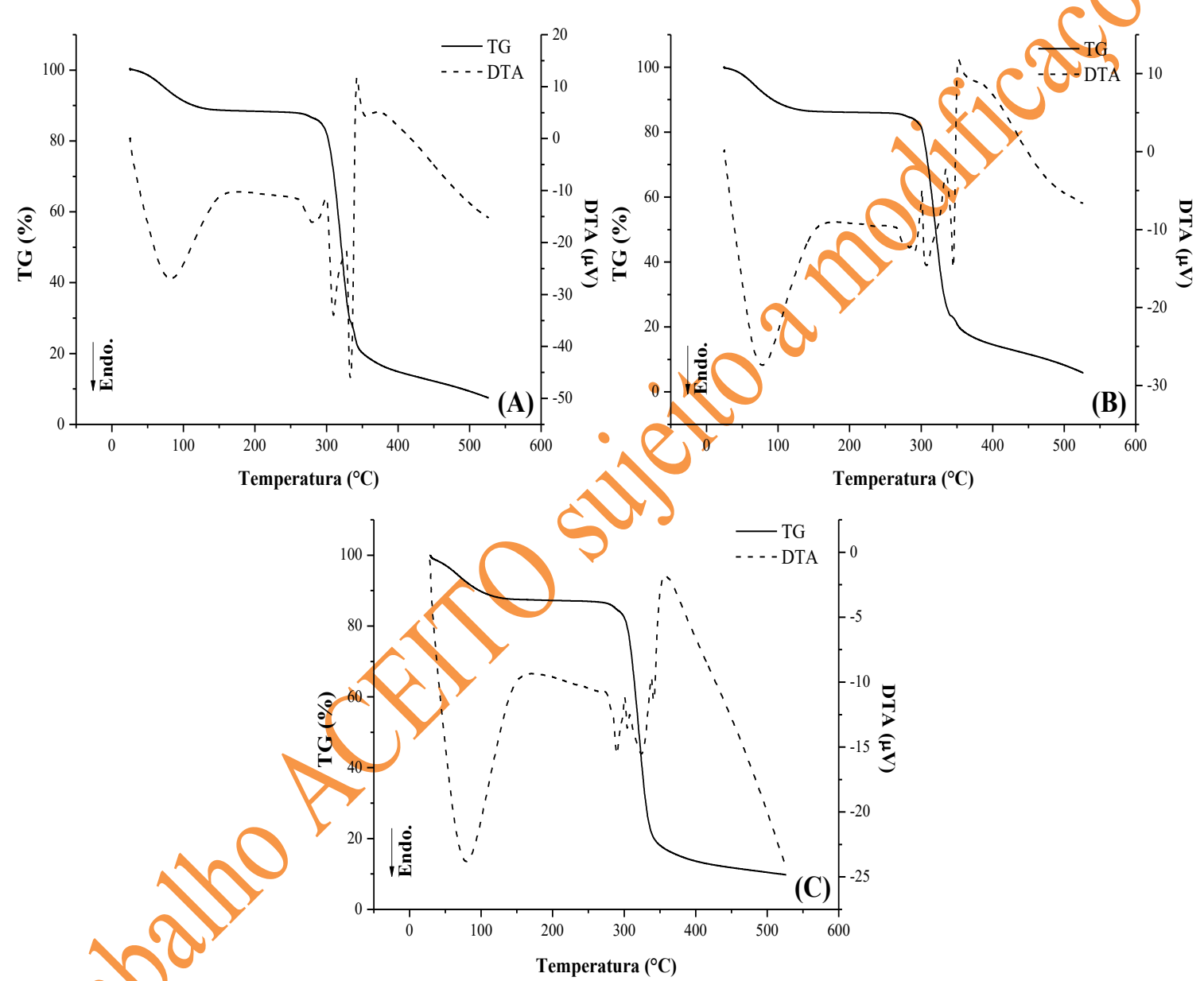

Figura 2. Curvas de TG e DTA para a fécula de mandioca variedade: (a) Pai Ambrósio, (b) Pocu e (c) Paulo Velho.

Os termogramas de gelatinização dos amidos das féculas das três variedades de mandioca são apresentados na Figura 3. A temperatura de inicio de gelatinização $\left(\mathrm{T}_{\mathrm{o}}\right)$ variou de $60,5^{\circ} \mathrm{C}$ a $68,3^{\circ} \mathrm{C}$, para os amidos das variedades Pai Ambrósio e Paulo Velho, respectivamente, porém as temperaturas de pico $\left(\mathrm{T}_{\mathrm{p}}=74,4 \pm 0,6^{\circ} \mathrm{C}\right)$ e final de gelatinização $\left(\mathrm{T}_{\mathrm{f}}=\right.$ $\left.84,0 \pm 0,5^{\circ} \mathrm{C}\right)$ dos amidos não apresentaram diferença estatística significativas $(\mathrm{p}>0,05)$. Abera \& Rakshit (2003) encontram valores médios de $\mathrm{T}_{\mathrm{o}}\left(65,5^{\circ} \mathrm{C}\right), \mathrm{T}_{\mathrm{p}}\left(70,4^{\circ} \mathrm{C}\right)$ e $\mathrm{T}_{\mathrm{f}}$ $\left(82,0^{\circ} \mathrm{C}\right)$, para amidos extraídos de três acessos de mandioca.

As entalpias de gelatinização $\left(\Delta \mathrm{H}_{\text {gel }}\right)$ dos amidos extraídos das mandiocas Pocu, Paulo Velho e Pai Ambrósio foram 10,1; 15,3 e 20,5 $\mathrm{J} / \mathrm{g}$, respectivamente. Nwokocha et al. (2009) 
observaram um valor médio de $14,3 \mathrm{~J} / \mathrm{g}$, para a entalpia de gelatinização de amidos nativos de mandioca. A maior $\Delta H_{\text {gel }}$ observada na gelatinização do amido da variedade Pai Ambrósio, sugere a presença de cadeias de amilopectina mais complexas na composição desse amido, o que favoreceu maior resistência à gelatinização, pois, quanto maior o comprimento das cadeias externas de amilopectina, maior o valor da entalpia de fusão do amido.

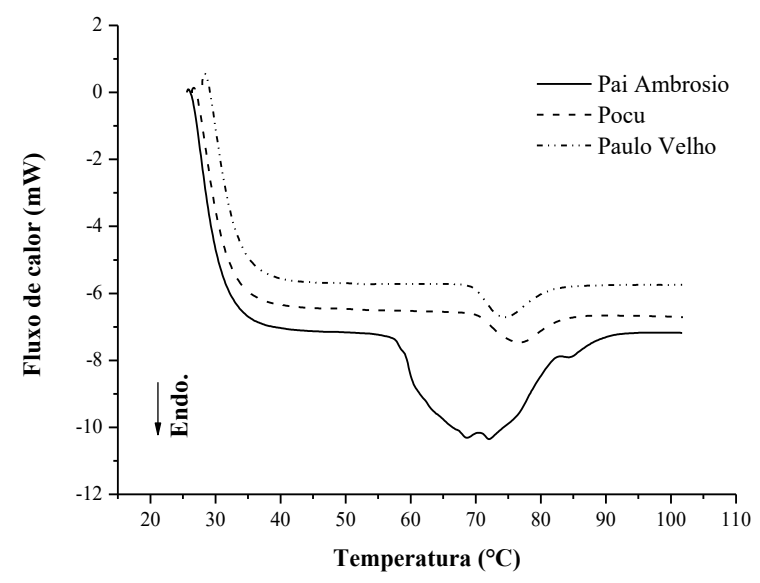

Figura 3. Termogramas DSC de gelatinização dos amidos das féculas de mandioca variedade Pai Ambrósio, Pocu e Paulo Velho.

\section{CONCLUSÕES}

As raízes das três variedades de mandioca estudadas não apresentam um padrão de tamanho e de forma. As yariedades de mandioca Paulo Velho e Pocu apresentam potencialidade para uso industrial, em função dos expressivos rendimentos em polpa e em fécula.

As féculas das três variedades de mandioca foram classificadas como "tipo 1", pela legislação brasileira, mas as variedades Pai Ambrósio e Pocu forneceram féculas com maior pureza em amido.

Os amidos das três féculas apresentam o mesmo padrão morfológico e de decomposição térmica, além de gelatinizarem na mesma faixa de temperatura.

\section{AGRADECIMENTOS}

Ao Conselho Nacional de Desenvolvimento Científico e Tecnológico (CNPq) e à Fundação de Amparo à Pesquisa do Estado do Pará (FAPESPA) pelo suporte financeiro.

\section{REFERÊNCIAS BIBLIOGRÁFICAS}

AACC. American Association of Cereal Chemists. Approved methods of the AACC. $9^{\text {th }}$ ed., St. Paul, 1995. 1200p.

Abera, S.; Rakshit, S.K. Comparison of physicochemical and functional properties of cassava starch extracted from fresh root and dry chips. Starch-Stärke, Glasgow, v.55, n.7, p.287-296, 2003.

Adetan, D.A.; Adekoya, L.O.; Aluko, O,B. Characterisation of some properties of cassava root tubers. Journal of Food Engineering, Davis, v.59, n. 4, p.349-353, 2003.

Aggarwal, P.; Dollimore, D.; Heon, K. Comparative thermal analyses study of two biopolymers, starches and cellulose. Journal of Thermal Analysis and Calorimetry, Budapest, v.50, n.1-2, p.7-17, 1997.

AOAC. Association of Official Analytical Chemists. Official methods of analysis of the AOAC International. $16^{\text {th }}$ ed. $3^{\text {rd }}$ rev, Washington: Arlington, 1997. 1141p.

BRASIL. Agência Nacional de Vigilância Sanitária. Resolução RDC n. 360, de 23 de dezembro de 2003. Regulamento técnico sobre rotulagem nutricional de alimentos embalados. Diário Oficial [da República Federativa do Brasil]. Brasília, 26 dez. 2003. Seção 1, p.4.

BRASIL. Ministério da Agricultura, Pecuária e Abastecimento. Instrução Normativa n. 23, de 14 de dezembro de 2005. Regulamento técnico de identidade e qualidade dos produtos amiláceos derivados da raiz da mandioca. Diário Oficial [da República Federativa do Brasil], Brasília, 15 dez. 2005. Seção 1, p.5.

Cereda, M.P.; Daiuto, E.R.; Vilpoux, O.F. Metodologia de determinação de amido por digestão ácida em microondas. Revista da Associação Brasileira dos Produtores de Amido de Mandioca, Paranavaí, v.2, n.8, p.29, 2004.

Cereda, M.P.; Vilpoux, O.F. Tecnologias, usos e potencialidades de tuberosas amiláceas latino americanas. Vol. 3. São Paulo: 
Fundação Cargill, 2003, 711p. (Série Cultura de tuberosas amiláceas latinoamericanas).

Charles, A.L.; Huang, T.C.; Lai, P.Y.; Chen, C.C.; Lee, P.P.; Chang; Y.H. Study of wheat flour-cassava starch composite mix and the function of cassava mucilage in chinese noodles. Food Hydrocolloids, Ucrânia, v.21, n.3, p.368-378, 2007.

Chisté, R.C.; Cohen, K.O.; Mathias, E.A.; Ramoa Jr., A.G.A. Estudo das propriedades físico-químicas e microbiológicas no processamento da farinha de mandioca do grupo d'água. Ciência e Tecnologia de Alimentos, Campinas, v.27, n.2, p.265-269, 2007.

Embrapa. Mandioca: o pão do Brasil. Brasília:

Garcia, V.; Colonna, P.; Lourdin, D.; Buleon, A.; Bizot, H.; Ollivon, M. Thermal transitions of cassava starch at intermediate water contents. Journal of Thermal Analysis, Budapest, v.47, n.5, p.1213-1228, 1996. Embrapa, 2005. 530p.

Jay, M.J. Microbiologia de alimentos. 6.ed. Porto Alegre: Artmed, 2005. 711p.

Leonel, M. Análise da forma e tamanho de grânulos de amidos de diferentes fontes botânicas. Ciência e Tecnologia de Alimentos, Campinas, v.27, n.3, p.579-588, 2007.

Nunes, L.B.; Santos, W.J.; Cruz, R.S. Rendimento de extração e caracterização química e funcional de féculas de mandioca da região do semi-árido baiano. Alimentos e Nutrição, Araraquara, v.20, n. 1, p. 129134, 2009.

Nwokocha, L.M.; Aviara, N.A.; Senan, C.; Williams, P.A.A. Comparative study of some properties of cássava (Manihot esculenta Crantz) and cocoyam (Colocasia esculenta, Linn) starches. Carbohydrate Polymers, Barking, v.76, n.3, p.362-367, 2009.

Ratnayake, W.S.; Jackson, D.S. A new insight - into the gelatinization process of native starches. Carbohydrate Polymers, Barking, v.67, n.4, p.511-529, 2007.

Gomes, C.N.; Carvalho, S.P.; Jesus, A.M.S.C Silva, P.A.; Cunha, R.L.; Lopes, A.S.; Pena, Custódio, T.N. Caracterização morfoagronômica e coeficientes de trilha de caracteres componentes da produção em mandioca. Pesquisa Agropecuária Brasileira, Brasília, v.42, n.8, p.1121-1130, 2007.
R.S. Caracterização de farinhas de tapioca produzidas no estado do Pará. Ciência Rural, Santa Maria, v.43, n.1, p.185-191, 2013. 